INTERGROUP ON THE WeLfare AND Conservation of ANIMALS

European Parliament, Brussels, A1GA

Wednesday 18 SePtember 2013, 15.00hrS

\title{
SPEECH
}

Ladies and gentlemen,

Mrs Pietikäinen,

Mr Zanoni,

I am delighted to join you today. It provides a good opportunity to look at some of the key animal welfare issues we are currently discussing or developing at EU level.

Let me start with a point on the EU's animal welfare strategy and the possibility it provides to propose a general animal welfare law. The purpose of such a law would be to support a new legal general framework for the welfare of animals, as well as making the EU's food industry more competitive.

In the meantime allow me to highlight some of the important preparatory work is already underway. A first stakeholder consultation was done in February and, thanks to European Parliament funding, the Commission also began a pilot project in January on a European network of reference centres called EUWeINet. 
The results of this exercise are expected by December and they will help to prepare the ground for the future EU network of reference centres for animal welfare. These centres will make a valuable contribution, providing important scientific and technical expertise to ensure a better application of the welfare rules.

The Commission has also ordered a study on education and information on animal welfare to determine which initiatives would be the most appropriate at EU level to promote animal welfare among the general public and consumers. The results of this are expected in May 2014.

In the meantime, the package of proposals we adopted in May would already lead to significant improvements in animal welfare:

- firstly, by strengthening the system of official controls;

- secondly, by improving the system for detecting and controlling animal disease.

In particular, the proposal: 
- 1. Clarifies that animal welfare controls are part of the multiannual national control plan (they should be planned, prioritised and accounted for);

- 2. Allows for the adoption by delegated acts of mandatory minimum frequencies and uniform modalities of official controls to verify compliance with animal welfare rules, mandatory measures in case of specific non-compliances, specific or additional tasks or responsibilities of competent authorities;

- 3. Acknowledges the need to use animal welfare indicators to perform official controls in cases where animal welfare is "non-quantifiable" and allows for the adoption of such indicators;

- 4. Enables the Commission to designate EU animal welfare reference centres providing scientific and technical assistance to the Commission and the Member States in relation to the application of animal welfare rules;

- 5. Improves the transparency by requesting Member States to:

- 6. Make available information on the organisation and performance of official controls; 
- 7. Publish timely and regularly information on official controls carried out, non-compliances, remedial actions and penalties.

On animal disease, the package also marks an important milestone for animal health, based on our principle that "prevention is better than cure."

It anticipates a common EU system to swiftly detect and control animal diseases and address animal health risks in a more strategic, risk-based and prioritised way. This will allow farmers, vets and authorities alike to better prevent, react to, and limit the spread and damage of diseases using a variety of tools, including vaccines.

Clearly, animal keepers have a key role to play in this respect: it is very important they are aware of animal health risks and we have clarified their responsibilities in the proposals too.

I firmly believe that this approach - a more proactive and preventive approach - will better support animal health and biosecurity. They will also contribute to better overall husbandry, better animal welfare, and possibly limit the use of antimicrobial medicines. 
I count on the support of this group to ensure the proposals make swift progress in the Parliament.

\section{Alternatives to animal testing}

On alternatives to animal testing, the Commission has taken a clear position in the Commission Communication of 11 March 2013, and has confirmed the Commission's commitment to let the full marketing ban in relation to animal testing enter into force.

This has given an important signal, also beyond Europe, in favour of animal welfare and innovative approaches to safety assessment.

This Communication also outlined the following upcoming priorities:

- Ensuring a coherent implementation of the 2013 marketing ban and monitoring its impacts;

- Continuing the support for research, development and validation of new alternative methods for human safety testing; 
- Making the European approach and alternative methods an integral part of the Union's trade agenda and international cooperation.

There are fears that the work on implementation may reopen the discussion on interpretation, but you can be assured that this work is essential to make sure that the ban is enforced and that this is done coherently with and by Member States.

On research and international cooperation we are working actively together with stakeholders on the issues outlined in the Commission Communication, to further advance ideas on how to involve other sectors.

Ladies and gentlemen,

\section{Enforcement}

Let me now say a few words on the enforcement of animal welfare rules. 
Firstly, on transport: The Council agreed that the main focus should be on ensuring proper enforcement of the current legislation.

In this context, the Commission's Decision on Member States' annual reports on their controls on animal transport will ensure that all findings are presented to the Commission in a harmonized manner. This will give us a clearer picture of where we are on implementing the rules, as well as the option to take targeted actions when necessary.

On top of this, the Commission continues to encourage EU countries to improve enforcement through a variety of measures:

- organising regular meetings of national experts;

- promoting guidelines for best practice among stakeholders;

- promoting best practice during FVO audits;

- initiating infringement proceedings against non-compliant EU countries. 
A second important area for enforcement is the pig Directive and the ban on individual sow stalls adopted in 2001. The 12 year transition period came to an end on the first of January this year, yet despite this, and based on the information we have received so far, only $13 \mathrm{EU}$ countries have achieved full compliance. We continue to investigate compliance in the remaining Member States and have already launched infringement procedures against $9 \mathrm{EU}$ countries in February.

We have requested all non-compliant countries to provide a summary of the actions taken or envisaged to achieve compliance. Based on their replies we will decide how to proceed and will not hesitate to take further steps against those who fail to make progress.

In addition to the group housing of sows, we have also started to develop guidelines on the protection of pigs. The aim is to achieve better implementation of the Directive's requirements on various issues, including the ban on routine tail-docking and the use of enrichment materials. 
Similarly, we are still following two EU countries closely for failing to implement the Directive on laying hens. In Italy and Greece, there are still cases of laying hens being kept in unenriched cages and both were referred to the European Court of Justice on 25 April for failing to fully comply with Union law.

Ladies and gentlemen,

An important tool for improving animal welfare and successfully enforcing the rules are the partnerships that exist between the different stakeholders and the knowledge sharing that takes place.

One such example is the European Declaration on alternatives to the surgical castration of piglets, a voluntary initiative by some of the main actors in the pigmeat sector to end surgical castration of male pigs by $1^{\text {st }}$ January 2018 .

The Commission mandated a series of technical and economic studies to support this objective and to encourage the use of alternatives to castration. Results of these studies are expected in 2014. 
In the meantime we are organising regular meetings with interested parties to help participants meet the 2018 deadline.

Reducing the castration of pigs will both improve animal welfare, and reduce the environmental impact of pig farming.

Similarly, the Commission has also been promoting enforcement of the new killing regulation which has applied since 1 January 2013.

We organised a conference on its implementation in October 2012, and a booklet that was produced in all EU languages has been downloaded hundreds of times from our website, contributing to a greater awareness of the new requirements.

The Commission is also preparing reports linked to this regulation, for example on poultry stunning and information to consumers on stunning.

And, for the first time - and responding to calls from the EP the Commission is also studying the welfare of pets involved in commercial practices. 
The primary objective of this work is to determine to what extent the Commission should take specific measures linked to the welfare of dogs and cats. The results of the study are expected by the end of 2014 .

The Commission is also organizing the "First EU Conference on dog and cat welfare" in Brussels on $28^{\text {th }}$ October 2013. May I remind you that this year the European Parliament and the Council have enacted legal instruments to enhance the movement of companion animals, for example using of common conditions for a common animal passport. A Schengen for animals!

And finally, before I conclude, a point on cloning:

The Commission confirms that in line with its 2013 work programme and based on the outcome of the impact assessment on cloning, it intends to adopt a stand-alone legislative proposal on cloning in this year.

The proposal will need to find a balanced and proportionate solution that can be implemented by all parties concerned, while considering that any provisions on this issue should be carefully thought through from a legal point of view. 
Ladies and gentlemen,

Finally, I would like to thank all MEPs for your support to the Commission in banning certain pesticides which were increasing the decline of the bee population in Europe.

I have touched on a variety of important issues but to conclude, I hope I have shown that the EU's thinking on animal welfare policy is changing. In the past, our focus was more on adopting specific legislation. The approach today is a more holistic one: we want to develop complementary initiatives that consider other elements beyond the rules alone.

Education, innovation, research and market mechanisms are both necessary and readily available tools for improving animal welfare. We work in close cooperation with EFSA and make full use of the EU research funded by the European Commission to improve our scientific knowledge.

Animal welfare reference centres will help to establish the effective use of this knowledge and achieve better enforcement and support. 
This Intergroup of the European Parliament has an important role to play, particularly given that animal welfare is not seen by EU citizens as a stand-alone issue but one that is integrated into the important concept of sustainability.

The Commission is willing to involve all partners to improve all aspects of animal welfare policy.

To this end I plan to organise an event at the beginning of next year to present, with the help of other stakeholders involved in the area of animal welfare, the main achievements made possible by the EU Animal Welfare Strategy that will have reached its midterm by then.

I hope that our common work will prepare an important legacy for the future Commission. Your contribution to the process is as always highly welcomed and indeed highly valued.

Thank you for your attention. I look forward to hearing your views and suggestions.

End 